\title{
Fabrication of Hybrid Surface Composite through Friction Stir Processing and Its Impression Creep Behaviour
}

\author{
S. Prakrathi, M. Ravikumar, K. R. Udupa, and K. Udaya Bhat \\ Department of Metallurgical and Materials Engineering, National Institute of Technology Karnataka, \\ Surathkal, Karnataka 575025, India \\ Correspondence should be addressed to K. Udaya Bhat; udayabhatk@gmail.com
}

Received 1 July 2013; Accepted 24 July 2013

Academic Editors: K. Hokamoto and E. J. Nassar

Copyright (C) 2013 S. Prakrathi et al. This is an open access article distributed under the Creative Commons Attribution License, which permits unrestricted use, distribution, and reproduction in any medium, provided the original work is properly cited.

Al-Ni in situ surface composites were fabricated by friction stir processing method. Friction stir processing produced a composite with nickel and $\mathrm{NiAl}_{3}$ as reinforcement particles in aluminium matrix. The particles were fine and were in the submicrometer size range. The separation distance between the particles was very small. Impression creep experiments were conducted on the samples both at friction stir zone and base material zone at various temperatures. Steady state creep rates were estimated, and activation energy for creep was calculated. It is observed that the friction stir zone offered a higher creep resistance compared to the base metal zone. Higher creep resistance is attributed to the dissolution of nickel atoms into aluminium matrix and the presence of fine nickel particles and $\mathrm{NiAl}_{3}$ precipitates. The measured activation energy indicated that the associated creep mechanism is the dislocation creep in the temperature range of $30-150^{\circ} \mathrm{C}$, both in friction stir zone and base metal zone. At higher temperatures $\left(150-180^{\circ} \mathrm{C}\right)$ the diffusion creep mechanism is suggested.

\section{Introduction}

Aluminum and its alloys have versatile properties which make them suitable for use in a variety of applications [1]. In many of the applications, the surface needs to have better mechanical properties like improved strength and better hardness. Having a metal matrix composite at the surface is one of the optiones to have better resistance to wear, improved hardness, and even to an extent high-temperature stability at the surface [2]. Friction stir processing (FSP) is a new metal working method for producing surface composite. It is based on the concept of friction stir welding (FSW) [3]. During friction stir processing, the stirred material undergoes severe plastic deformation. The material flow associated with stirring and severe plastic deformation can be used for bulk alloy modification by the mixing of second elements, mixing followed by the precipitation of second phases, distribution of fine particles of second element, increased density of defects, and so forth. As a result, the stirred zone becomes a metal matrix composite with an improved hardness and wear resistance [4].

Arora et al. [5] have reviewed composite fabrication using FSP route. Mishra et al. [6] have used this route to make a surface composite on AA 5083 alloy with $0.7 \mu \mathrm{m} \mathrm{SiC} \mathrm{particles.}$ Shafiei-Zarghani et al. [7] and Mahmoud et al. [8] have incorporated $\mathrm{Al}_{2} \mathrm{O}_{3}$ and $\mathrm{SiC}$ particles to substrates like $\mathrm{Al}, \mathrm{Cu}$, and $\mathrm{Fe}$ alloys and observed an improvement in the abrasion and wear resistance of the surface composite. Ma and Mishra [9] have investigated the stability of the $\mathrm{SiC}$ reinforced aluminium matrix composite. Dolatkhah et al. [10] have investigated the mechanical and microstructural properties of Al-SiC metal matrix composites fabricated by FSP. Lee et al. [11] have investigated the microstructure and mechanical properties of $\mathrm{Al}-\mathrm{Fe}$ in situ nanocomposite produced by friction stir processing. Hsu et al. [12] have reported the processing of $\mathrm{Al}-\mathrm{Ti}$ and $\mathrm{Al}-\mathrm{Cu}$ composites and in both systems formation of intermetallics is reported. Yadav and Bauri [4, 13] have reported the fabrication of aluminum matrix composite with Ni dispersion using FSP route. They have reported a composite without a detectable range of aluminides. Ke et al. [14] have produced Al-Ni intermetallics by friction stir processing and reported in situ formation of $\mathrm{Al}_{3} \mathrm{Ni}$ and a mixture of $\mathrm{Al}_{3} \mathrm{Ni}$ and $\mathrm{Al}_{3} \mathrm{Ni}_{2}$ after heat treatment. It also contained some Ni particles. Particle size range was varying from submicrometers to a few tens of micrometers. Qian et al. [15] have synthesised $\mathrm{Al}_{-} \mathrm{Al}_{3} \mathrm{Ni}$ in situ composites using FSP route 
and tried to explain its formation using concept of effective change in Gibbs free energy. They have also reported that the composite has better hardness and tensile properties.

To investigate the creep behaviour of these composites, impression creep testing is a suitable method [16]. Impression creep test offers several advantages over the conventional creep test. It takes a shorter duration for the test and only a small quantity of the testing material is sufficient. The temperature and stress dependency of creep rate could be obtained with a minimum number of samples. More importantly, it is the most suitable test method to study the creep behaviour of parent and processed zones independently [16]. To the best of our understanding, there is no report on the creep behaviour of $\mathrm{Al}$ matrix composite produced by FSP route. This paper reports the investigation of creep behaviour of friction stir processed Al-Ni surface composites investigated using impression creep technique.

\section{Materials and Methods}

Commercial pure $\mathrm{Al}$ sheet $5 \mathrm{~mm}$ thickness was used as the substrate material for friction stir processing. Base metal had coarse grains (average grain size $\sim 160 \mu \mathrm{m}$ ) without any second phase particles (Figure 1(a)). Surface of the base metal was made rough to hold the powder during friction stirring. Approximately, 1 gram (per centimeter length of the sample) of electrolytic Ni powder was added on to the groove made on the substrate. Figure 1(b) shows the initial morphology of the nickel powder used. Ni powder was incorporated into the matrix using a friction tool made from tool steel. The following are the tool dimensions: shoulder diameter $-20 \mathrm{~mm}$, pin diameter $-6 \mathrm{~mm}$, and pin depth $-3 \mathrm{~mm}$. The following are the FSP parameters used: tool rotation speed $-1200 \mathrm{rpm}$, tool travel speed $-18 \mathrm{~cm} / \mathrm{min}$, and normal force $-10 \mathrm{kN}$.

Using a precision sample cutting machine, the sample was cut perpendicular to the processing zone, and the cut surface was polished using standard metallographic techniques and etched to reveal the macrostructure. Figure 2 shows the macrostructure.

The macrostructural study reveals two distinct zones, namely, friction stirred zone and base metal zone. They are identified as FSZ (marked by A in Figure 2) and BMZ (marked by B in Figure 2), respectively. Using a scanning electron microscope (SEM), microstructural features were investigated both in FSZ and BMZ. Energy dispersive spectroscopy (EDS) attached to SEM was used for the investigation of chemical composition in FSZ. Phase identification in FSZ was done using X-ray diffraction (XRD) techniques.

Impression creep experiments were carried out both at FSZ and BMZ using a tungsten carbide indentor. A sketch of the tungsten carbide indentor used is shown in Figure 3. During experiments, the indentor was made to penetrate the sample (either at FSZ or BMZ). These locations are shown as $A$ and $B$ in Figure 2. A normal load of $5 \mathrm{~kg}$ was used during the impression test. On a $2 \mathrm{~mm}$ diameter contact area this gave a stress of about $15.6 \mathrm{MPa}$ which is much less compared to yield strength of $\mathrm{Al}$ [17]. During impression experiments, the depth of the penetration of the indentor into the specimen was measured continuously using a linear variable differential transducer (LVDT). Impression creep experiments were done for the duration of 180 minutes, and it is believed that this time is sufficient to attain steady state creep conditions. A plot of impression depth versus time (i.e., creep curve) was drawn. The creep experiments were conducted at various temperatures, namely, $30^{\circ} \mathrm{C}, 100^{\circ} \mathrm{C}$, $150^{\circ} \mathrm{C}$, and $180^{\circ} \mathrm{C}$, for the purpose of estimating the activation energy and understanding the creep mechanism.

\section{Results and Discussion}

3.1. Microstructure and Phases in the Friction Stir Processed Zone. Figure 4 is a SEM micrograph from the FSP zone (A in Figure 2). The second phase particles are uniformly distributed without any clustering. Figure 5 shows a magnified micrograph from Figure 4. The SEM image in Figure 5 indicates that the particles show two types of contrast, namely, white contrast (B) and grey contrast (A). The chemical analysis using EDS indicates that the bright region (B) is nickel and the grey region $(\mathrm{A})$ is $\mathrm{NiAl}_{3}$. It clearly indicates that the surface of the commercial aluminum substrate has changed to a hybrid composite using friction stir processing route. Pure nickel and nickel aluminide $\left(\mathrm{NiAl}_{3}\right)$ are the reinforcing phases in the surface of the aluminum. The nickel particles are added into the matrix by using $\mathrm{FSP}$, and $\mathrm{NiAl}_{3}$ has formed in situ during FSP. Also, EDS analysis in some locations in matrix $\mathrm{Al}$ indicates that some amount of $\mathrm{Ni}$ dissolved in $\mathrm{Al}$. As much as $13 \% \mathrm{Ni}$ is detected in some locations by SEM-EDS.

Particle size of a large number of particles as observed at a magnification of 2000x was measured using SigmaScan software (Jandel Scientific), and it is plotted in Figure 6. The particles are very fine and a major fraction of the particles has a size range which is less than $0.5 \mu \mathrm{m}$. From Figure 5, it may be noted that the spacing between the particles is in the range of $2-3 \mu \mathrm{m}$. Figure 7 shows XRD plot of FSP zone. The data clearly shows presence of $\mathrm{Ni}$ in elemental form as well as in the intermetallic form $\left(\mathrm{Al}_{3} \mathrm{Ni}\right)$.

Microstructural study along with EDX (Figure 5) and XRD analysis in the friction stirred zone (Figure 7) reveal the presence of undissolved $\mathrm{Ni}$ - and $\mathrm{Al}-\mathrm{Ni}$-based second phase particles. Al-Ni system has a number of intermetallics, namely, $\mathrm{Al}_{3} \mathrm{Ni}, \mathrm{Al}_{3} \mathrm{Ni}_{2}, \mathrm{Al}_{3} \mathrm{Ni}_{5}$, and $\mathrm{AlNi}_{3}$ [18]. It is to be noted that the equilibrium solubility of $\mathrm{Ni}$ in $\mathrm{Al}$ does not exceed 0.04 at\% [18]. The large extent of $\mathrm{Ni}$ dissolution in $\mathrm{Al}$ as observed during EDS analysis is attributed to the nonequilibrium nature of friction stir processing. Nonequilibrium phenomena during friction stir welding are reported by many investigators [19-21].

Yadav and Bauri $[4,13]$ have reported the fabrication of aluminum matrix composite with $\mathrm{Ni}$ dispersion using FSP route. They did not report the formation of any of the Al-Ni intermetallics during FSP. Formation of $\mathrm{Al}_{3} \mathrm{Ni}$ during friction stirring is reported by Ke et al. [14] and Qian et al. [15]. Sieber et al. [22] have reported the reactive formation of $\mathrm{NiAl}_{3}$ intermetallics at the interface of Al-Ni when sheets of Al-Ni are cold rolled and heat treated. They also observed a thin layer of $\mathrm{Al}_{3} \mathrm{Ni}_{2}$ at the interface of $\mathrm{Al}-\mathrm{Al}_{3} \mathrm{Ni}$ layer, after heat treatment. 


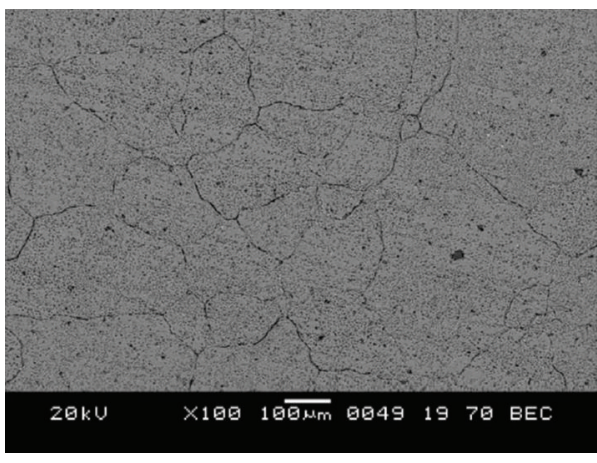

(a)

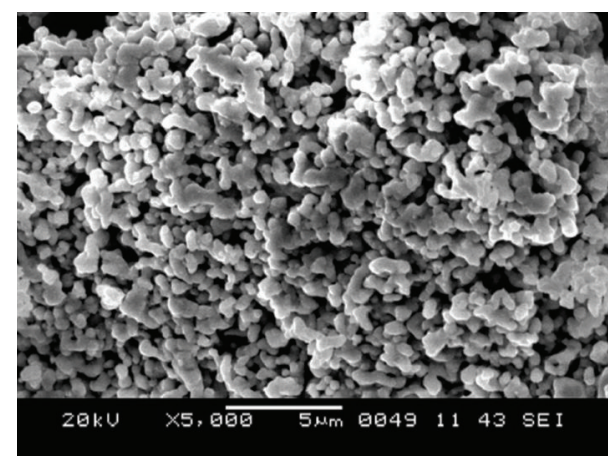

(b)

Figure 1: Initial condition of the substrate and powder materials. (a) Microstructure of the Al substrate showing coarse grains; (b) initial morphology of the nickel powder used.

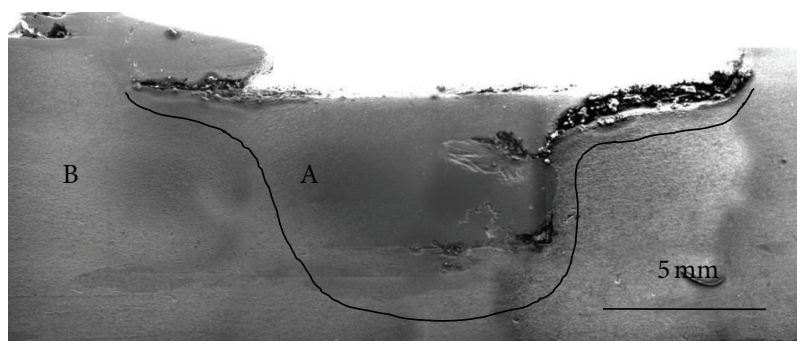

FIgURE 2: Macroview of the cross section of the friction stir processed sample (A), base metal zone (B).

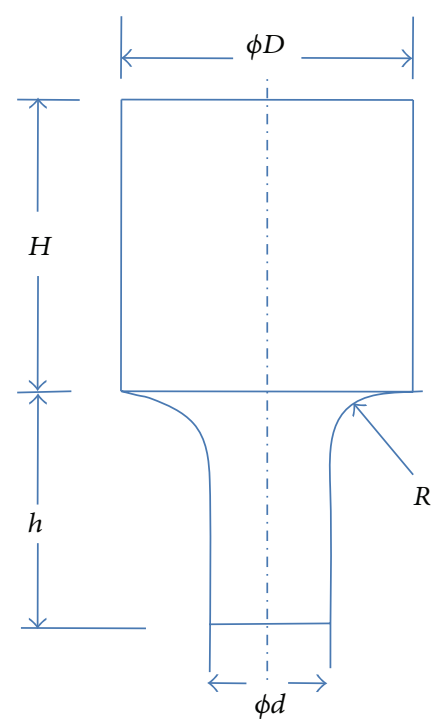

$D=6, d=2$,

$H=8, h=10, R=2.5$

(all dimensions in $\mathrm{mm}$ )

$R$

FIgURE 3: Dimensions of the indentor used for impression creep experiments.

Arora et al. [5] have observed that large plastic strain in FSP can shear the metal powders. It can also break oxides on the surface of the particles, causing intimate contact between the matrix and the reinforcement particles, promoting reaction at the interface. The tendency for particles agglomeration is reduced as particles are covered by a layer of matrix material. High plastic strain imposed on the matrix material

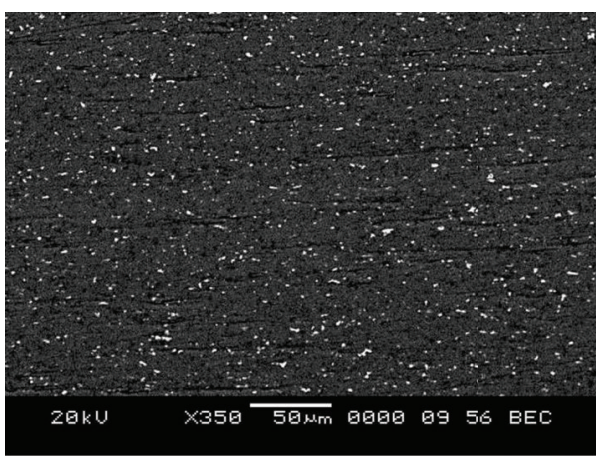

FIGURE 4: Micrograph showing distribution of the particles.

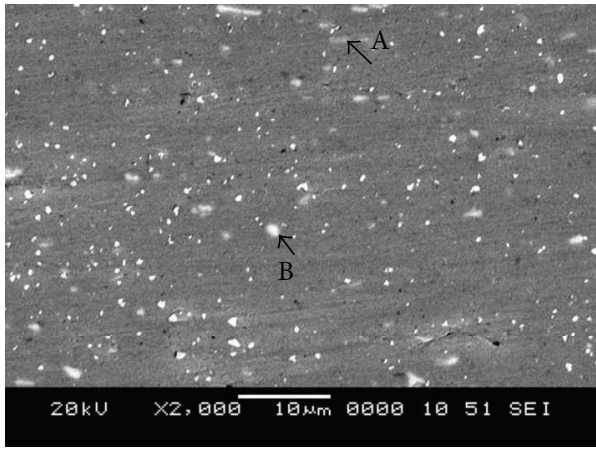

FIgURE 5: A magnified micrograph from Figure 4 indicating two types of particles (A and $\mathrm{B})$. The EDS analysis indicates that the particles are $\mathrm{Ni}(\mathrm{B})$ and $\mathrm{NiAl}_{3}(\mathrm{~A})$.

promotes particle size reduction and their distribution, and it also increases diffusion rate of elements, thus accelerating the reaction rate between the matrix and the particles [5, 15]. Extremely fine reinforcement particles act as pinning sites and help in controlling the grain structure during recrystallisation. FSP also provides a higher temperature to facilitate the formation of intermetallic phases in situ and accelerate the reaction $[5,21]$. All these processes in tandem produce a surface with the dispersion of fine particles of nickel and nickel aluminide. 


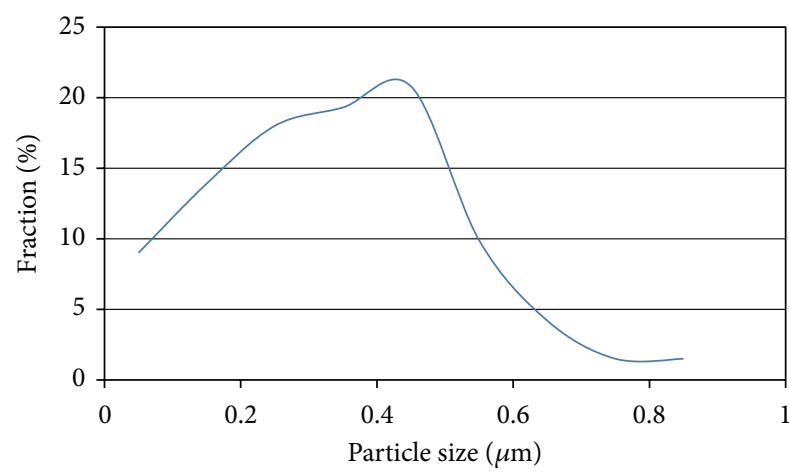

Figure 6: Particle size distribution of the reinforcing particles observed at 2000x magnification.

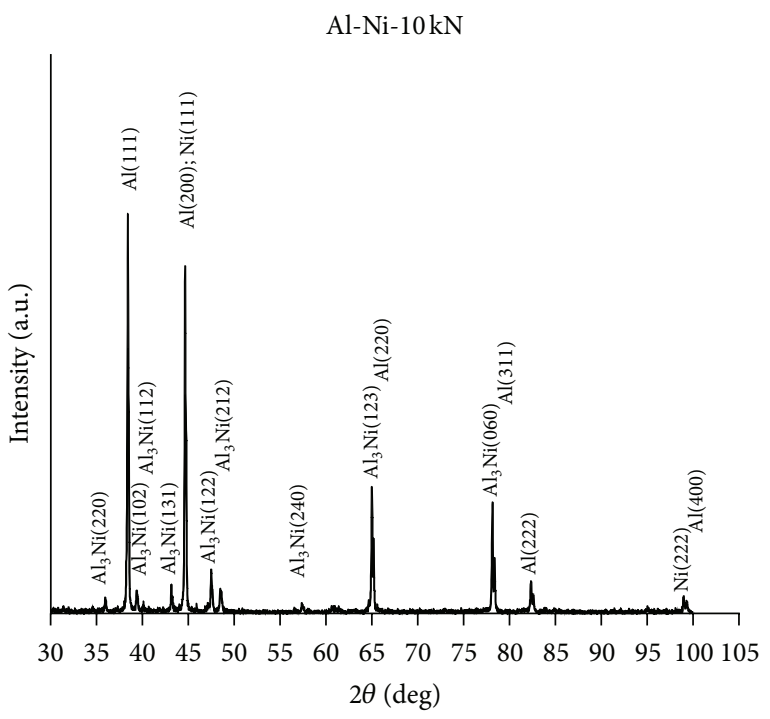

FIGURE 7: XRD analysis of friction stir processed region.

3.2. Impression Creep Behaviour. In the impression creep experiments, a calculated load was applied on the indentor positioned at the desired location in the sample (i.e., friction stir zone or base metal zone). The penetration depth was measured continuously as a function of time, and a creep curve of depth versus time is drawn. A curve for the conditions of room temperature and FSZ for the load of $5 \mathrm{~kg}$ is shown in Figure 8. Similar curves were generated both for FSZ and $\mathrm{BMZ}$ at various temperatures and were used in the analysis.

Using the values of penetration depth and indenter diameter, indentation creep strain was estimated for each curve, following the approach presented by Sastry [16]. Using these plots, steady state creep rates $(\dot{\varepsilon})$ were estimated as follows:

$$
\Delta \varepsilon=\frac{\Delta l}{D}
$$

where $\Delta \varepsilon$ is the incremental creep strain in the secondary stage of the creep curve profile and $\Delta t$ is the corresponding incremental time, $\Delta l$ is the incremental penetration depth, and $D$ is the indentor diameter [16]. The values of steady state creep rate for the case of base metal and friction stirred regions at different temperatures are given in Table 1 (load:

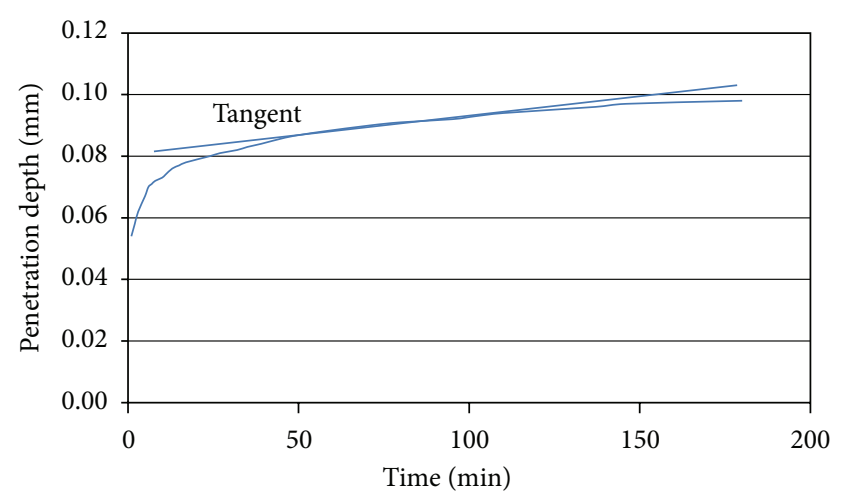

Figure 8: Penetration depth of the indenter as a function of time. FSZ, room temperature, and $5 \mathrm{~kg}$ load.

TABLE 1: Steady state creep rates in friction stirred zone and base metal (load: $5 \mathrm{~kg}$ ).

\begin{tabular}{lcc}
\hline \multirow{2}{*}{ Temperature $\left({ }^{\circ} \mathrm{C}\right)$} & \multicolumn{2}{c}{ Steady state creep rate $\left(\mathrm{min}^{-1}\right)$} \\
& Base metal region & Friction stirred region \\
\hline 30 & $3 \times 10^{-5}$ & $8.33 \times 10^{-6}$ \\
100 & $30.4 \times 10^{-5}$ & $8.7 \times 10^{-5}$ \\
150 & $200 \times 10^{-5}$ & $90 \times 10^{-5}$ \\
180 & $235.7 \times 10^{-5}$ & $178.9 \times 10^{-5}$ \\
\hline
\end{tabular}

$5 \mathrm{~kg}$ ). We see that the steady state creep rate value increases as temperature increases, and this is shown in Figure 9.

The following observations could be made from the data presented in Figure 9.

(1) Creep rates are lower in the friction stirred region than the base metal region at almost all temperatures.

(2) Creep rates are low at lower temperatures but they increased exponentially with temperature both for base metal and friction stirred regions.

Activation energy for creep $(Q)$ is calculated by using the following equation:

$$
Q=\frac{R \ln \left(\dot{\varepsilon}_{1} / \dot{\varepsilon}_{2}\right)}{1 / T_{2}-1 / T_{1}},
$$

where $R$ is the gas constant and $\dot{\varepsilon}_{1}$ and $\dot{\varepsilon}_{2}$ are the steady state creep rates at temperature $T_{1}$ and $T_{2}$, respectively. The values of the activation energy for the impression creep of the friction stirred region and base metal region were estimated, and they are in the range of $45 \mathrm{~kJ} / \mathrm{mole}$ to $55 \mathrm{~kJ} / \mathrm{mole}$ in the temperature range of $30-150^{\circ} \mathrm{C}$. Comparing them with the activation energy of the movement of dislocations in $\mathrm{Al}$ alloys, it could be inferred that the underlying creep mechanism is the dislocation creep, both in the substrate and FSP zones. In the temperature range of $30-150^{\circ} \mathrm{C}$, the thermal activation affects the lattice resistance to the glide of the dislocation. The temperature-dependent variation of the creep rate is related to the thermally assisted force required to overcome the obstacles lying in the plane of the dislocation glide. Thus, it is arguably inferred that the dislocation creep 


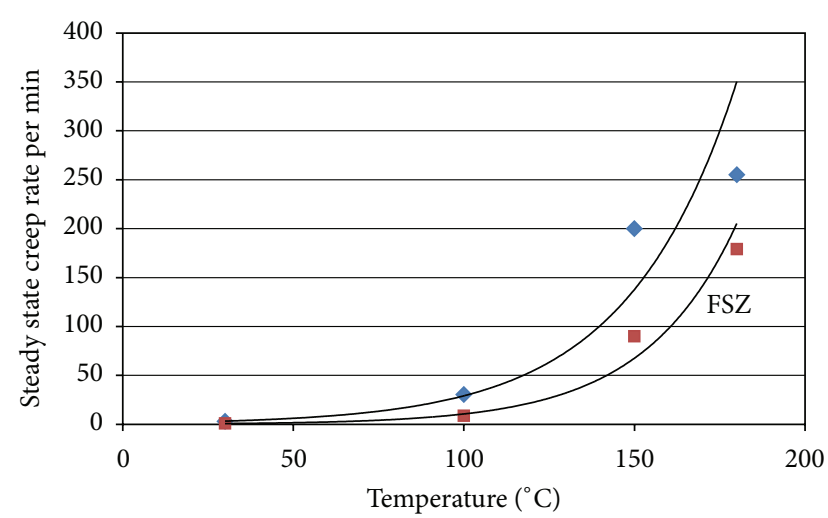

FIGURE 9: Variations of steady state creep rate $\left(\times 10^{-5}\right)$ as a function

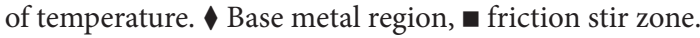

dominates the mechanism of creep in $\mathrm{Al}$ base metal and friction stirred zones. The lower value of activation energy is mainly attributed to the nonequilibrium nature of the material due to friction stir processing. Presence of a large amount of dislocations and very fine grain scales makes the dislocation glide easier, by providing a large number of closely spaced sinks (in the form of grain boundaries).

The activation energy determined is in the range of $140 \mathrm{~kJ} / \mathrm{mole}$ to $170 \mathrm{~kJ} / \mathrm{mole}$ in the temperature range of 150 $210^{\circ} \mathrm{C}$. It is very close to the activation energy for self-diffusion $(143.4 \mathrm{~kJ} / \mathrm{mole})$ in aluminium $[23,24]$. For this reason, rate controlling mechanism at elevated temperatures, in both the friction region, and base metal region has been ascribed to the diffusion creep. Diffusional creep is influencing creep behaviour $[25,26]$.

Higher creep resistance offered by the friction stirred region compared to base metal region is ascribed to the following reasons:

(1) presence of nickel atoms into Al matrix by mechanical alloying,

(2) precipitation of $\mathrm{Al}_{3} \mathrm{Ni}$ precipitates,

(3) dislocations created by friction stir processing.

Higher level of creep resistance is exhibited by friction stir processed zone compared to base metal zone even at an elevated temperature. It suggests that second phase particles play an important role in the creep mechanism over the temperature range investigated. They act as barriers for dislocation movement. The hindrance to the dislocation movement is related to the distribution of particles and interface between the particles and the matrix [20,21]. Fine particles, small interparticle separation distance, and good particle matrix bonding are essential for strengthening. Yadav and Bauri [4] have reported that the interface in $\mathrm{Al}-\mathrm{Ni}$ composite produced by FSP is good and it hinders the dislocation motion.

\section{Conclusions}

Hybrid surface composite was made on a commercial pure aluminium by incorporating nickel particles using the friction stir processing route. The composite region consisted of fine nickel and nickel aluminide particles produced in situ during friction stir processing. The dispersed particles were fine and uniformly distributed in the processed region. Impression creep experiments were done using a tungsten carbide indenter of a $2 \mathrm{~mm}$ diameter at temperatures in the range of $30-180^{\circ} \mathrm{C}$. Plots of indentation creep depth as a function of time were obtained, and these plots were used for estimating the steady state creep rate. It is observed that the steady state creep rate is lower in friction stirred zone compared to base metal zone at all temperatures. Activation energy for creep was estimated and it was observed that at the temperature range of $30-150^{\circ} \mathrm{C}$, the dislocation creep is predominant, and at higher temperatures the diffusion creep is playing a major role.

\section{Acknowledgments}

The authors thank Dr. G. Phanikumar and Mr. H. K. Raffi, IIT Madras, for helping in carrying out friction stir processing.

\section{References}

[1] R. E. Smallman and R. J. Bishop, Modern Physical Metallurgy and Materials Engineering, Butterworth Publishing, New York, NY, USA, 6th edition, 1999.

[2] T. P. D. Rajan, R. M. Pillai, and B. C. Pai, "Functionally graded $\mathrm{Al}-\mathrm{Al}_{3} \mathrm{Ni}$ in situ intermetallic composites: fabrication and microstructural characterization," Journal of Alloys and Compounds, vol. 453, no. 1-2, pp. L4-L7, 2008.

[3] R. S. Mishra and Z. Y. Ma, "Friction stir welding and processing," Materials Science and Engineering R, vol. 50, no. 1-2, pp. $1-78,2005$

[4] D. Yadav and R. Bauri, "Nickel particle embedded aluminium matrix composite with high ductility," Materials Letters, vol. 64, no. 6, pp. 664-667, 2010.

[5] H. S. Arora, H. Singh, and B. K. Dindaw, "Composite fabrication using friction stir processing-a review," The International Journal of Advanced Manufacturing Technology, vol. 61, no. 9-12, pp. 1043-1055, 2012.

[6] R. S. Mishra, Z. Y. Ma, and I. Charit, "Friction stir processing: a novel technique for fabrication of surface composite," Materials Science and Engineering A, vol. 341, no. 1-2, pp. 307-310, 2003.

[7] A. Shafiei-Zarghani, S. F. Kashani-Bozorg, and A. Zarei-Hanzaki, "Microstructures and mechanical properties of $\mathrm{Al} / \mathrm{Al}_{2} \mathrm{O}_{3}$ surface nano-composite layer produced by friction stir processing," Materials Science and Engineering A, vol. 500, no. 1-2, pp. 84-91, 2009.

[8] E. R. I. Mahmoud, K. Ikeuchi, and M. Takahashi, "Fabrication of $\mathrm{SiC}$ particle reinforced composite on aluminium surface by friction stir processing," Science and Technology of Welding and Joining, vol. 13, no. 7, pp. 607-618, 2008.

[9] Z. Y. Ma and R. S. Mishra, "Cavitation in superplastic $7075 \mathrm{Al}$ alloys prepared via friction stir processing," Acta Materialia, vol. 51, no. 12, pp. 3551-3569, 2003.

[10] A. Dolatkhah, P. Golbabaei, M. K. Besharati Givi, and F. Molaiekiya, "Investigating effects of process parameters on microstructural and mechanical properties of $\mathrm{Al} 5052 / \mathrm{SiC}$ metal matrix composite fabricated via friction stir processing," Materials and Design, vol. 37, pp. 458-464, 2012.

[11] I. S. Lee, P. W. Kao, and N. J. Ho, "Microstructure and mechanical properties of $\mathrm{Al}-\mathrm{Fe}$ in situ nanocomposite produced by 
friction stir processing," Intermetallics, vol. 16, no. 9, pp. 11041108, 2008.

[12] C. J. Hsu, P. W. Kao, and N. J. Ho, "Intermetallic-reinforced aluminum matrix composites produced in situ by friction stir processing," Materials Letters, vol. 61, no. 6, pp. 1315-1318, 2007.

[13] D. Yadav and R. Bauri, "Processing, microstructure and mechanical properties of nickel particles embedded aluminium matrix composite," Materials Science and Engineering A, vol. 528, no. 3, pp. 1326-1333, 2011.

[14] L. Ke, C. Huang, L. Xing, and K. Huang, "Al-Ni intermetallic composites produced in situ by friction stir processing," Journal of Alloys and Compounds, vol. 503, no. 2, pp. 494-499, 2010.

[15] J. Qian, J. Li, J. Xiong, F. Zhang, and X. Lin, "Insitu synthesizing $\mathrm{Al} 3 \mathrm{Ni}$ for fabrication of intermetallic reinforced aluminium alloy composites by friction stir processing," Materials Science and Engineering A, vol. 550, pp. 279-285, 2012.

[16] D. H. Sastry, "Impression creep technique-an overview," Materials Science and Engineering A, vol. 409, no. 1-2, pp. 67-75, 2005.

[17] R. A. Higgins, Engineering Metallurgy, Arnold Publishing, New York, NY, USA, 6th edition, 1993.

[18] H. Baker and H. Okamoto, ASM Handbook, vol. 3 of Alloy Phase Diagrams, ASM International, Materials Park, Ohio, USA, 1992.

[19] M. Atapour, A. Pilchak, G. S. Frankel, and J. C. Williams, "Corrosion behaviour of investment cast and friction stir processed Ti-6Al-4V,' Corrosion Science, vol. 52, no. 9, pp. 3062-3069, 2010.

[20] C. W. Yang, “Tensile mechanical properties and failure behaviors of friction stir processing (FSP) modified $\mathrm{Mg}-\mathrm{Al}-\mathrm{Zn}$ and dual-phase Mg-Li-Al-Zn alloys," in Materials Science: Advanced Topics, Y. Mastai, Ed., InTech, 2013.

[21] C.-F. Chen, P.-W. Kao, L. Chang, and N.-J. Ho, "Mechanical properties of nanometric $\mathrm{Al} 2 \mathrm{O} 3$ particulate-reinforced $\mathrm{Al}$ $\mathrm{Al}_{11} \mathrm{Ce} 3$ composites produced by friction stir processing," Materials Transactions, vol. 51, no. 5, pp. 933-938, 2010.

[22] H. Sieber, J. S. Park, J. Weissmüller, and J. H. Perepezko, "Structural evolution and phase formation in cold-rolled aluminumnickel multilayers," Acta Materialia, vol. 49, no. 7, pp. 1139-1151, 2001.

[23] F. A. Mohamed and T. G. Langdon, "Deformation mechanism maps based on grain size," Metallurgical Transactions, vol. 5, no. 11, pp. 2339-2345, 1974.

[24] Y. Li and T. G. Langdon, "Creep behavior of an Al-6061 metal matrix composite reinforced with alumina particulates," Acta Materialia, vol. 45, no. 11, pp. 4797-4806, 1997.

[25] H. Takagi, M. Dao, M. Fujiwara, and M. Otsuka, "Experimental and computational creep characterization of Al-Mg solid-solution alloy through instrumented indentation," Philosophical Magazine, vol. 83, no. 35, pp. 3959-3976, 2003.

[26] O. D. Sherbi and J. Wordsworth, "Deformation processing and structure," in ASM Handbook, chapter 8, American Society for Metals, Metal Park, Ohio, USA, 1984. 

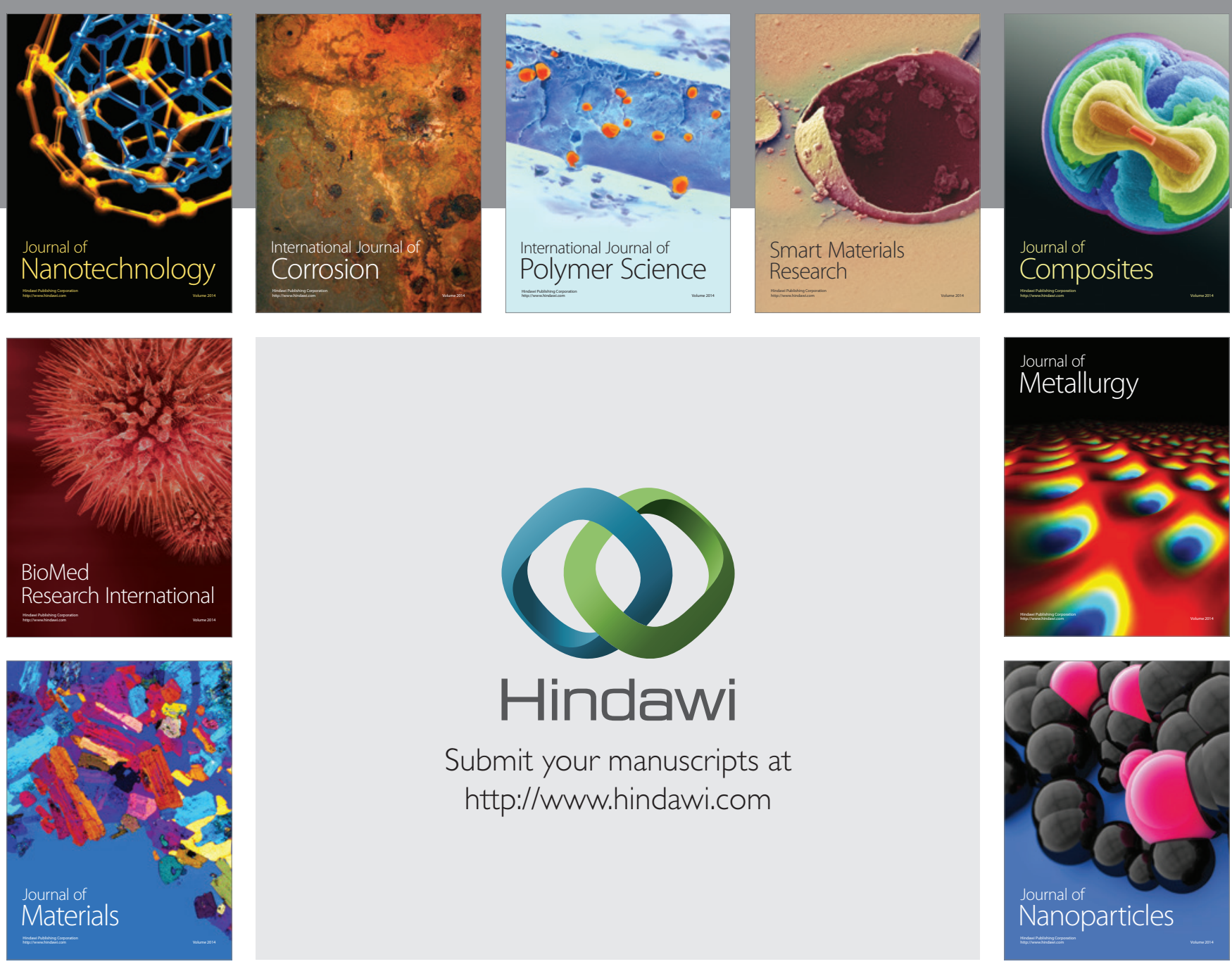

Submit your manuscripts at http://www.hindawi.com
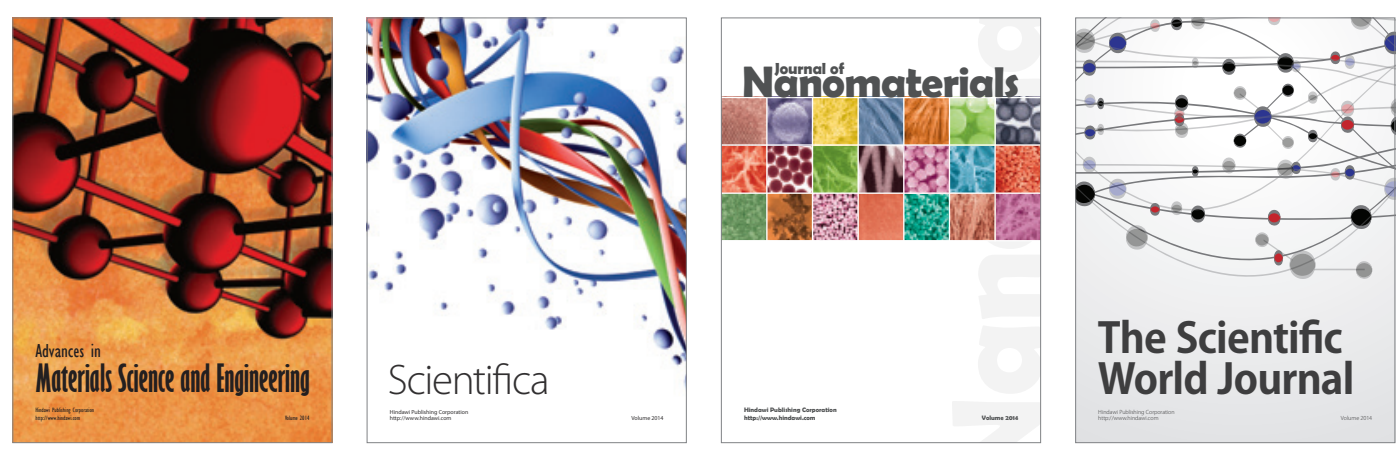

\section{The Scientific World Journal}
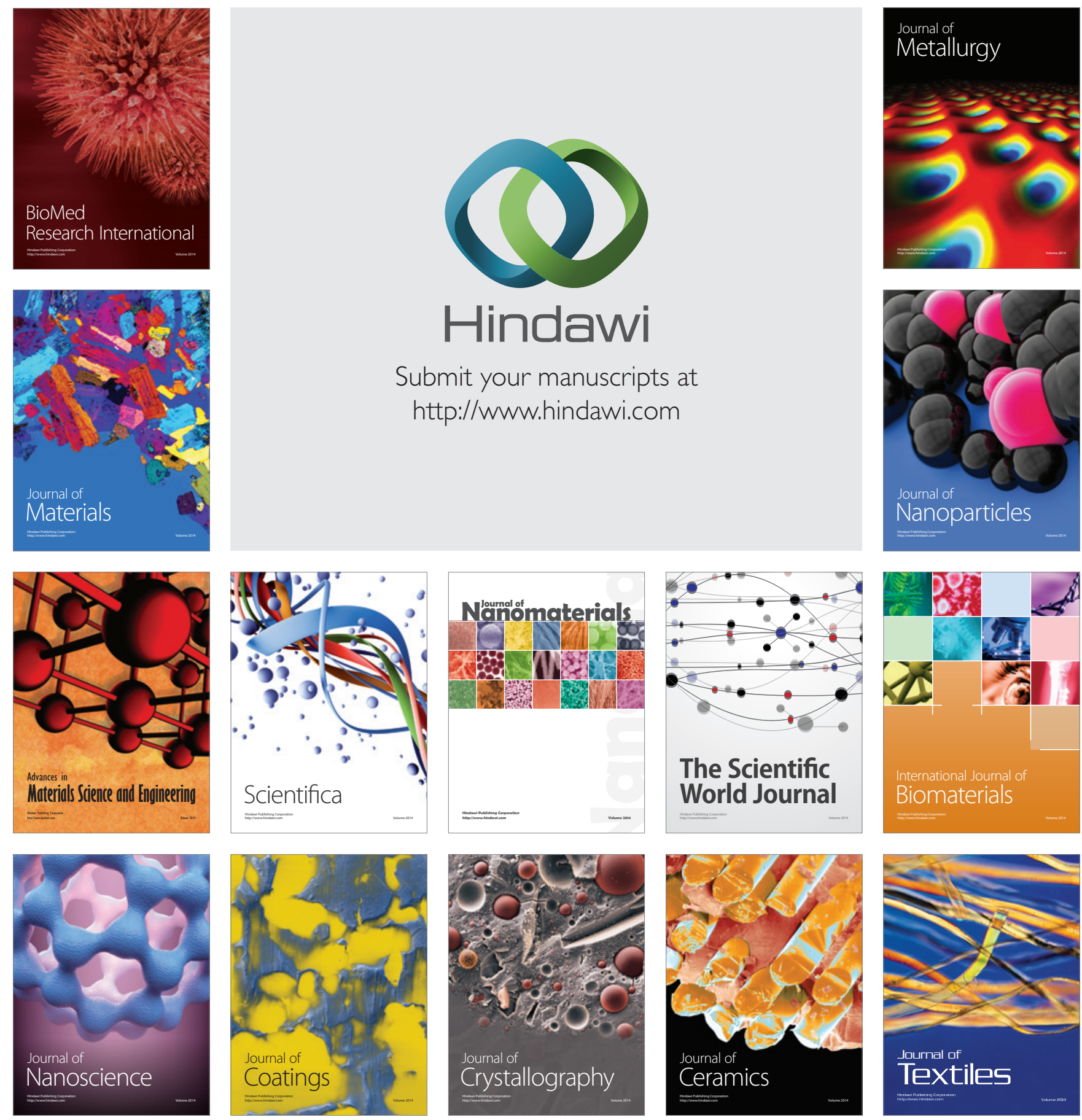